\title{
Diamond forming fluids from Kankan, Guinea: major and trace element study
}

\author{
Y. Weiss ${ }^{1}$, R. Kessel ${ }^{1}$, W. L. Griffin ${ }^{2}$, I. Kiflawi ${ }^{1}$, D. R. Bell ${ }^{3}$, \\ J. W. Harris ${ }^{4}$ and $O$. Navon ${ }^{1}$ \\ ${ }^{1}$ Institute of Earth Sciences, The Hebrew University of Jerusalem, Israel \\ ${ }^{2}$ ARC National Key Centre for Geochemical Evolution and Metallogeny of Continents (GEMOC), Macquarie \\ University, NSW, Australia \\ ${ }^{3}$ School of Earth and Space Exploration, Arizona State University, Tempe, AZ, USA \\ ${ }^{4}$ Division of Earth Sciences, University of Glasgow, Glasgow, Scotland
}

The association of some diamonds with metasomatic minerals and with veins and alteration zones in xenoliths, as well as their morphology and internal symmetric textures suggest the involvement of fluids in their formation. Infrared spectroscopy and EPMA of microinclusion-bearing diamonds revealed that the microinclusions trapped high-density fluids (HDFs) with compositions varying along two arrays between three end-members: carbonatitic, hydrous-silicic and hydrous-saline. The carbonatitic end-member is further divided into high- and low-Mg members (Klein BenDavid et al., 2008). Klein-BenDavid et al. (2007, 2008) suggested evolution from the high- through the low-Mg carbonatite to silicic and saline HDFs by crystallization of silicates and carbonates and liquid immiscibility. Most diamonds sample only a small fraction of the HDF evolution and zoned diamonds with a significant radial variation in inclusion composition are exceptional. The investigation of such zoned diamonds, including their trace elements characteristics is important for constraining the source and chemical evolution of diamond-forming fluids.

\section{The diamonds}

We report here an extensive major and trace element study of seven coated diamonds from the Kankan district in Guinea. Major elements were analyzed using both EPMA and LA-ICP-MS. The good agreement between the two techniques validates the accuracy of both (Rege et al., 2005; Weiss et al., 2008). Water and $\mathrm{CO}_{2}$ contents were determined using FTIR.

In four diamonds (ON-KAN-384, 386, 388 and 389) the inner coat hosts abundant micro-inclusions while the outer part is clear (Fig. 1a). CL imaging reveals uniformly dull luminescence throughout both zones (Fig. 1b). In ON-KAN-382 the number density of inclusions increases outwards. The coats of ON-KAN381 and 383 are zoned with sharp boundaries that are seen optically and in CL images (Figure 1c, d). The core of ON-KAN-383 carries tens of mineral inclusions. Raman spectroscopy and EPMA document almandine garnet, omphacitic clinopyroxene, coesite, rutile and low-Ni monosulfide-solid-solution, clearly indicating that the core grew in an eclogitic host rock.
In general, the octahedral cores of the diamonds carry nitrogen in A and B centers, indicating long residence times in the mantle. The coats carry nitrogen in A centers, but in the rims of ON-KAN-381, 382 and 383 bands at 1344 and $1130 \mathrm{~cm}^{-1}$ identify the presence of single nitrogen atoms in $C$ centers (Figure 2). This sequence indicates a long time gap between the formation of the cores and coats, a shorter time gap between the inner and outer coats, and a very short mantle residence time after growth ended.
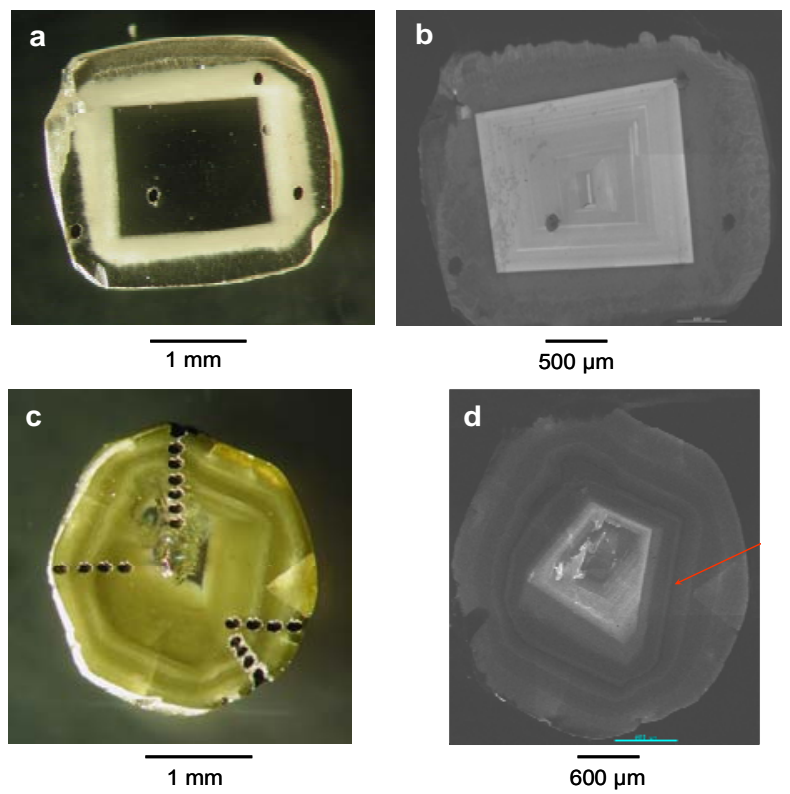

Figure 1: Photographic and CL images of diamonds ON-KAN-386 (a, b) and ON-KAN-381 (c, d). Holes are laser ablation analysis spots. The arrow points to the core-coat boundary.

\section{The High-Density Fluids}

Four of the diamonds (ON-KAN-384, 386, 388 and 389) trapped high-Mg carbonatitic HDFs. These diamonds are homogenous and the HDFs do not show a significant compositional variation from the inner coat to the rim. However, in three diamonds we found small increases in $\mathrm{CaO}$ and $\mathrm{MgO}$ towards the rim. The uniform CL suggests a single growth event. Thus, fluid evolution from silicic to carbonatitic during this growth 
event contradicts the prediction of the fractionation model (Klein BenDavid et al., 2008).

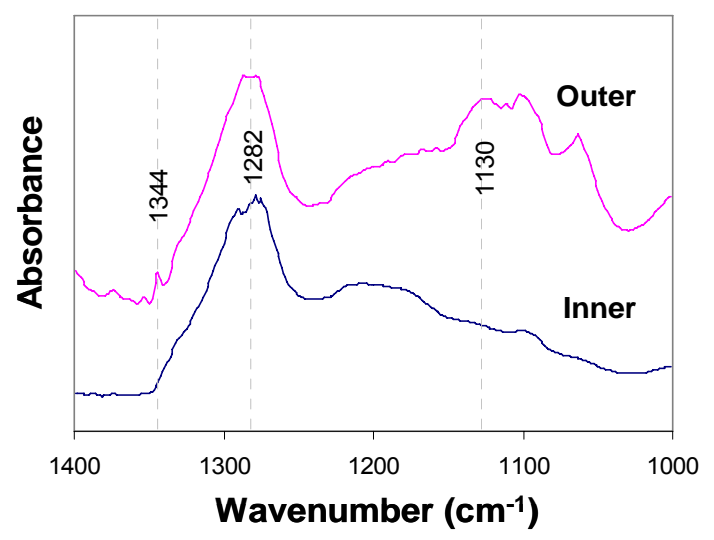

Figure 2: IR spectra of the inner and outer parts of the coat of diamond ON-KAN-381 showing the presence of $\mathrm{A}$ and $\mathrm{C}$ nitrogen centers. While in the inner coat nitrogen exist only in A centers $\left(1282 \mathrm{~cm}^{-1}\right)$, the outer part also carries $C$ centers (1130 and $1344 \mathrm{~cm}^{-1}$ ).

The HDFs in the other three diamonds vary between low-Mg carbonatitic and silicic composition. Diamond ON-KAN-382 carries HDFs of silicic composition, whereas the two zoned diamonds exhibit strong chemical zoning, from silicic inner parts to a carbonatitic outer part (Fig. 3). Clear borders separate the various zones. Radial compositional variations within the zones are also clear and reveal evolution in contrasting directions. These contrasting trends together with the presence of nitrogen $C$ centers only in the outer zones indicate multiple growth events with complex evolution of HDF chemistry. The above conclusion agrees with previous reports of two diamonds with zoning in HDF composition by Klein BenDavid et al. (2004) and Shiryaev et al. (2005). They attributed the clear zoning to diamond growth from fluids of different chemical and carbon isotopic composition.

Crystallization, melting, immiscibility and interaction with the wall-rock are all possible mechanisms for the evolution of the HDFs (Schrauder and Navon, 1994; Izraeli et al., 2001; Tomlinson et al., 2005; Klein BenDavid et al., 2007, 2008; Zedgenizov et al., 2007). The detailed information presented here, and especially the contrasting evolution from carbonatitic to silicic and vice-versa show that no single model describes all diamonds. Each of the above suggestions may play a role in diamond formation within the mantle and/or in the evolution of the various components. The contrasting trends of evolution in different diamonds and in different zones of the same diamond (Figure 3) call for diamond growth during mixing of fluids that evolved at different locations. Such mixing is not necessarily mechanical; it may occur by differing degrees of metasomatic interaction between HDF and its wall rock, including melting triggered by introduction of an HDF into a hot solid rock.

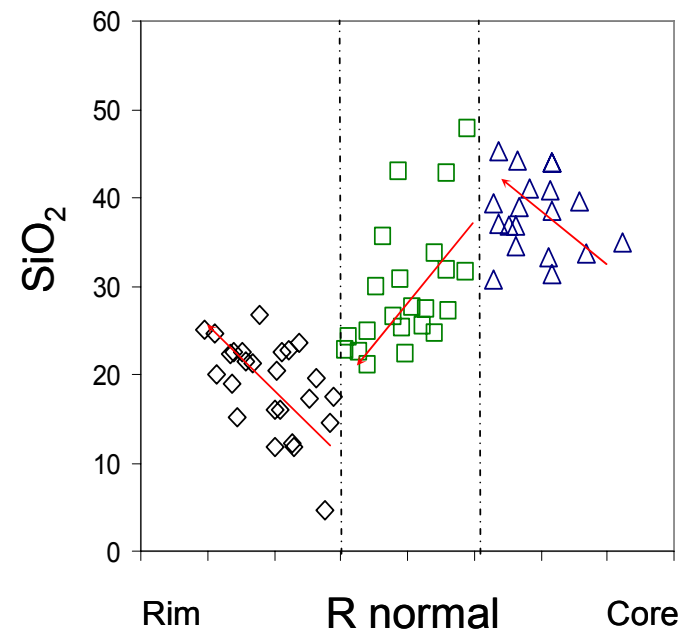

Figure 3: Chemical composition of microinclusions in diamond ON-KAN-381 along a radial profile from core to rim: triangles - inclusions in the inner coat, squares - in the middle coat, diamonds - outer coat. The dotted lines mark the borders between the three parts. The normalized radius provides the position of individual inclusions relative to these borders.

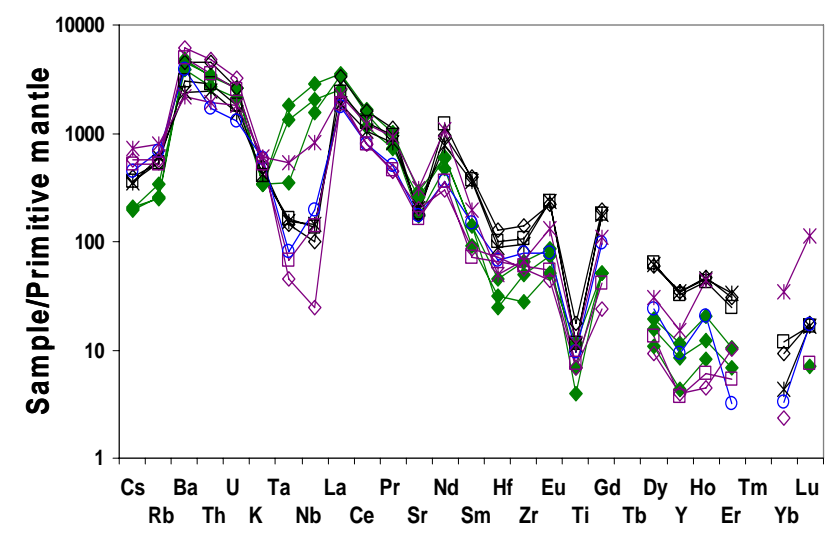

Figure 4: Trace element compositions of high-Mg carbonatitic to hydrous silicic HDF in Kankan diamonds. Solid diamonds - high-Mg carbonatitic, stars - low-Mg carbonatitic, open symbols - more silicic HDFs. The Nb anomaly deepens in the more silicic HDFs.

All diamonds, including the various parts of the two zoned diamonds, have elevated levels of incompatible elements. Relative to primitive mantle composition, the HDF are rich in $\mathrm{Ba}$, Th, $\mathrm{U}$ and LREE compared to the alkalis (K, Cs and Rb), HFSE (Ta, Nb, Hf, Zr, Ti) and $\mathrm{Sr}$ and $\mathrm{Y}$. (Figure 4).

Compared to the low-Mg carbo-silicic HDFs, the high$\mathrm{Mg}$ carbonatitic fluids have the lowest content of alkalis, HFSE (Zr, Hf and Ti) and Y but the highest Nb and Ta concentration. They also exhibit the highest (Ba, Th, U)/alkalis and LREE/MREE and HREE (Figure 4, 5). In many plots of such concentrations and their ratios, the high-Mg carbonatitic HDFs deviate from the clear trend formed by the low-Mg carbosilicic diamonds (Figure 5). 

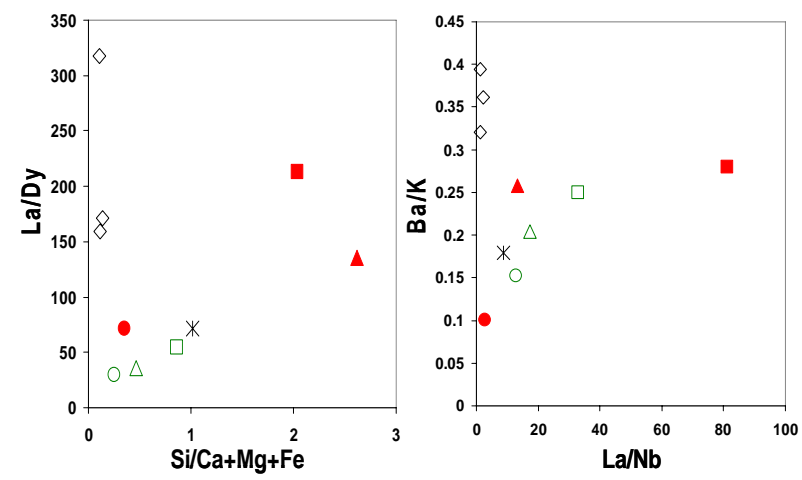

Figure 5: Trace element ratios and $\mathrm{Si} /(\mathrm{Ca}+\mathrm{Mg}+\mathrm{Fe})$ showing the difference between the high-Mg carbonatitic and the low-Mg carbo-silicic HDFs in Kankan diamonds. Open diamonds - high-Mg carbonatitic HDFs, star - ON-KAN-382; circles - HDFs in the outer parts; triangles - the middle parts and squares - the inner parts of ON-KAN-381 (open symbols) and ON-KAN-383 (solid symbols).

\section{Discussion}

We suggest that the differences between the HDFs reflect their different sources and mode of formation. The high-Mg carbonatitic HDF is a product of interaction between saline fluids and peridotitic source rocks (Navon et al., 2008), while the low-Mg carbosilicic HDFs may reflect derivation from an eclogitic source. The eclogitic mineral assemblage in the core of ON-KAN-383 supports this scenario.

Melting of carbonated eclogites produces a range of silicic to Ca-rich carbonatitic melts (Yaxley and Green, 1994; Yaxley, 1999; Hammouda 2003), while carbonated peridotite produces Mg-rich carbonatitic melts (Wallace and Green, 1988; Dalton and Presnall, 1998). In principle, it is possible to explain the range of fluids by melting these two sources, and even grow the silicic inner coat before the carbonatitic rims. However, the contrasting trends in and between the parts of the two zoned diamonds, as well as the extreme enrichment in incompatible elements call for a more complex scenario that involves additional sources and mixing of HDFs.

Some garnet inclusions in Kankan octahedral diamonds exhibit a sinusoidal REE pattern, interpreted by Stachel et al. (2000) as the result of metasomatic interaction between the garnet and a fluid with extremely steep REE pattern. The very steep pattern of the high-Mg carbonatitic HDF, with $(\mathrm{La} / \mathrm{Dy})_{\mathrm{CN}}$ reaching 380, comes within the range of calculated melts in equilibrium with the Kankan garnets with the sinusoidal patterns (La/Dy=200-650). Saline HDF from Diavik, Canada associated with high-Mg carbonatitic HDFs, similar to those from Kankan, have even higher values $(\mathrm{La} / \mathrm{Dy}=440)$ and could also induce such patterns in the diamonds. If the diamonds that trap the garnets were formed during such metasomatic event (Bell et al, 2005, Malkovets et al., 2007), then similar fluids may promote the growth of both fibrous and octahedral diamonds in the Earth's mantle.

\section{References}

Bell, D.R., Gregoire, M., Grove, T.L. et al., 2005, Silica and volatile-element metasomatism of Archean mantle: A xenolith-scale example from the Kaapvaal Craton: Contributions to Mineralogy and Petrology, 150, 251267,

Hammouda, T. 2003. High-pressure melting of carbonated eclogite and experimental constraints on carbon recycling and storage in the mantle. Earth and Planetary Science Letters, 214, 283-297.

Izraeli, E.S., Harris, J.W., Navon, O., 2001. Brine inclusions in diamonds: a new upper mantle fluid. Earth and Planetary Science Letters, 187, 323-332.

Klein-BenDavid, O., Izraeli, E.S., Hauri, E., Navon, O., 2004. Mantle fluid evolution - a tale of one diamond. Lithos, 77, 243 - 253.

Klein-BenDavid, O., Izraeli, E.S., Hauri, E., Navon, O., 2007. Fluid inclusions in diamonds from the Diavik mine, Canada and the evolution of diamond-forming fluids. Geochemica et Cosmochemica Acta, 71, 723-744.

Klein-BenDavid, O., Logvinova, A. M., Sobolev, N. V., et al., 2008. Yakutian Diamond-forming fluids - the evolution of carbonatitic high density fluids. 9th IKC, Extended Abstracts.

Malkovets, V.G., Griffin, W.L., O’Reilly, S.Y., Wood, B.J., 2007. Diamond, subcalcic garnet and mantle metasomatism: Kimberlite sampling patterns define the link. Geology, 35, 339-342.

Navon, O., Weiss, Y., Klein BenDavid, O., 2008. Diamond forming fluids: their origin and evolution. 9th IKC, extended abstracts.

Rege, S., Jackson, S., Griffin et al., 2005. Quantitative traceelement analysis of diamond by laser ablation inductively coupled plasma mass spectrometry. Journal of Analytical Atomic Spectrometry, 20, 601-611.

Schrauder, M., Navon, O., 1994. Hydrous and carbonatitic mantle fluids in fibrous diamonds from Jwaneng, Botswana. Geochemica et Cosmochemica Acta, 58, 761771.

Shiryaev, A., Izraeli, E.S., Hauri, E., Galimov, E., and Navon, O., 2005. Chemical, optical and isotopic investigation of fibrous diamonds from Brazil. Russian Geology and Geophysics, 46, 1207-1222.

Stachel, T., Brey, G.P., Harris, J.W., 2000. Kankan diamonds (Guinea) I: from the lithosphere down to the transition zone. Contributions to Mineralogy and Petrology, 140, 16-27.

Tomlinson, E., De Schrijver, I., De Corte, K. et al., 2005. Trace element compositions of submicroscopic inclusions in coated diamond: A tool for understanding diamond petrogenesis. Geochemica et Cosmochemica Acta, 69, 4719-4732.

Wallace, M. E., Green, D. H., 1988. An experimental determination of primary carbonatite magma composition. Nature, 335, 343-346.

Weiss, Y., Griffin, W. L., Elhlou, S., Navon, O. (in press). Comparison between LA-ICP-MS and EPMA analysis of trace elements in diamonds. Chemical Geology.

Yaxley, G.M., Green, D.H., 1994. Experimental demonstration of refractory carbonate-bearing eclogite and siliceous melt in the subduction regime. Earth and Planetary Science Letters, 128, 313-3

Yaxley, G.M., 1999. Phase relations in carbonated eclogite under upper mantle PT conditions - implications for carbonatite petrogenesis In: Gurney, J., Gurney J, Pascoe, M., Richardson, S. (Eds.), Proceedings 7th IKC. Red Roof Designs, Cape Town, 933-947. 